\section{Secukinumab efficacy in patients with PsA is not dependent on patients' body mass index}

We read with interest the recently published paper from McGonagle et $a l^{1}$ analysing the role of interleukin (IL)-17A in axial spondyloarthritis and psoriatic arthritis (PsA). The metaanalysis and functional study provided by the authors highlighted the efficacy of IL-17A block by secukinumab in the treatment of PsA. However, there is no mention of the role of body mass index (BMI), if any, in influencing the clinical response to secukinumab, given the lack of published data. PsA is a chronic inflammatory arthritis burdened by a series of metabolic comorbidities. Among them, obesity is very common in PsA, with a prevalence of $27 \%$, as confirmed by a recent Spanish work. ${ }^{2}$ Obesity in PsA has been associated with higher disease activity and a worse effectiveness of biologic treatment in PsA. This has been certainly proven for anti-tumour necrosis factor (TNF)- $\alpha$ as demonstrated by different studies reporting, in obese patients, a reduced treatment response and adherence. In particular, results coming from DAN-BIO and ICE-BIO registries ${ }^{3}$ point out that obesity is a risk factor for anti-TNF withdrawal due to poor response. Although a recent multicentric, retrospective study in Spain has shown that obese subjects with psoriasis have a poor therapeutic response to secukinumab, ${ }^{4}$ no data are currently available for secukinumab in obese patients with PsA.

Our studies focused on the relationship between BMI and clinical response to secukinumab in PsA. We prospectively analysed 100 patients with PsA (57\% female, median age 53 (49.2-55.0 years) satisfying Classification Criteria for Psoriatic Arthritis (CASPAR) criteria $^{5}$ for PsA, afferent to our clinics, who were treated with secukinumab. Patients were divided into two groups based on BMI $(\mathrm{BMI}<25$ normal weight and $\mathrm{BMI} \geq 25$ overweight/obese). In the normal-weight group, $75 \%$ were female; the median age was 50.5 (41.054.6); the median BMI was 22 (20.2-23.3); and the median Disease Activity in PSoriatic Arthritis (DAPSA) was 19.19 (15.6-24.2). The features of the overweight/obese patients were similar to those of the normal-weight group (48\% were female, median age 54 (50-59), median BMI 29 (27.4-30.1) and median DAPSA 21.2 (19.0-24.4)). Clinical response to therapy, evaluated as the achievement of low disease activity or remission according to DAPSA, was recorded 6 months after starting treatment. After 6 months of treatment, the variation of the DAPSA was inversely related to BMI: overweight/ obese patients had in fact a better response to secukinumab compared with normal-weight patients (figure 1A,B). By using a correlation coefficient (Statistical Package for Social Science (SPSS)) to analyse the degree of association between BMI and DAPSA, we confirmed that BMI and DAPSA were inversely related in patients with PsA $(p=0.05)$ in our study.

Interestingly, analysis of serum levels of IL-17 in 20 obese patients compared with 20 non-obese patients showed significantly higher serum levels of IL-17 in the former (figure 1C), indicating IL-17 as a key cytokine driving inflammation in obese patients with PsA. As far as we are concerned, these are the first data about clinical response to secukinumab in obese patients with PsA. Obesity has been shown to promote the expansion of IL-17-producing $\mathrm{T}$ cells in adipose and peripheral tissues. ${ }^{6}$ In addition, in patients affected by metabolic syndrome, the levels of IL-17R expression in the liver or muscles are correlated with insulin resistance. ${ }^{6}$ Our results support the relevance of IL-17 in driving systemic inflammation in obese patients with PsA, also providing evidence that obese patients may have a better response to secukinumab compared with non-obese patients. Interestingly, this effect was not influenced by the secukinumab dosage. In conclusion, although further studies are required to confirm our data, these findings indicate a close relationship between IL-17, obesity and PsA, possibly supporting the idea that obesity might be one relevant clinical factor driving the choice of secukinumab in overweight/obese patients.

Ilenia Pantano $\odot,{ }^{1}$ Daniela Iacono, ${ }^{1}$ Ennio Giulio Favalli, ${ }^{2}$ Giuseppe Scalise, ${ }^{1}$ Luisa Costa, ${ }^{3}$ Francesco Caso, ${ }^{3}$ Giuliana Guggino, ${ }^{4}$ Raffaele Scarpa, ${ }^{3}$ Francesco Ciccia ${ }^{1}$
A

\begin{tabular}{|c|c|c|c|c|}
\hline & & & $\begin{array}{l}\text { continuous } \\
\text { BMI }\end{array}$ & DAPSA T6 \\
\hline \multirow{6}{*}{$\begin{array}{l}\text { Kendall's tau } \\
\text { coefficient }\end{array}$} & \multirow[t]{3}{*}{ Continuous BMI } & correlation coefficient & 1,000 & $0.135^{*}$ \\
\hline & & 1-TAIL SIGNIFICANCE & - & 0.028 \\
\hline & & $\mathrm{N}$ & 100 & 93 \\
\hline & \multirow[t]{3}{*}{ DAPSA T6 } & correlation coefficient & $0.135 *$ & 1,000 \\
\hline & & 1-TAIL SIGNIFICANCE & 0.028 & - \\
\hline & & $\mathrm{N}$ & 93 & 93 \\
\hline \multirow{6}{*}{$\begin{array}{l}\text { Spearman's } \\
\text { rho }\end{array}$} & \multirow[t]{3}{*}{ Continuous BMI } & correlation coefficient & 1,000 & $0.192^{*}$ \\
\hline & & 1-TAIL SIGNIFICANCE & - & 0.032 \\
\hline & & $\mathrm{N}$ & 100 & 93 \\
\hline & \multirow[t]{3}{*}{ DAPSA T6 } & correlation coefficient & $0.192^{*}$ & 1,000 \\
\hline & & 1-TAIL SIGNIFICANCE & 0.032 & - \\
\hline & & $\mathrm{N}$ & 93 & 93 \\
\hline
\end{tabular}

B Correlation BMI vs DAPSA 6 months


Figure 1 Correlation between BMI and DAPSA and serum IL-17 levels in PsA obese and non-obese patients. (A) Correlation between BMI and DAPSA by Kendall's tau coefficient and Spearman's rho tests ( ${ }^{*}$ statistical significance is for values of 0.05 , one tail). (B) Graphical representation of correlation between BMI and DAPSA by Spearman test. (C) Analysis of serum levels of IL-17 in 20 obese and 20 obese and 20 non-obese patients compared to 30 healthy controls. BMI, body mass index; HC, health control; IL, interleukin; PsA, psoriatic arthritis. 
${ }^{1}$ Department of Precision Medicine, Section of Rheumatology, University della Campania L Vanvitelli, Naples, Italy

${ }^{2}$ Department of Rheumatology, Gaetano Pini Institute, Milan, Italy

${ }^{3}$ Department of Clinical and Experimental Medicine, Rheumatology Research Unit, University of Naples Federico II School of Medicine and Surgery, Napoli, Campania, Italy

${ }^{4}$ Department of Health Promotion, Mother and Child Care, Internal Medicine and Medical Specialties, University of Palermo, Palermo, Italy

Correspondence to Professor Francesco Ciccia, Reumatologia, Università degli Studi della Campania Luigi Vanvitelli, Napoli, Campania, Italy; francesco.ciccia@unicampania.it

Contributors All authors worked to write the paper.

Funding The authors have not declared a specific grant for this research from any funding agency in the public, commercial or not-for-profit sectors.

Competing interests None declared.

Patient and public involvement Patients and/or the public were not involved in the design, or conduct, or reporting, or dissemination plans of this research.

Patient consent for publication Not required.

Provenance and peer review Not commissioned; internally peer reviewed.

(c) Author(s) (or their employer(s)) 2020. No commercial re-use. See rights and permissions. Published by BMJ.

\section{Check for updates}

To cite Pantano I, lacono D, Favalli EG, et al. Ann Rheum Dis Epub ahead of print: [please include Day Month Year]. doi:10.1136/annrheumdis-2020-217251

Received 28 February 2020

Accepted 1 March 2020

Ann Rheum Dis 2020;0:1-2. doi:10.1136/annrheumdis-2020-217251

\section{ORCID iD}

Ilenia Pantano http://orcid.org/0000-0002-6671-6621

\section{REFERENCES}

1 McGonagle DG, McInnes IB, Kirkham BW, et al. The role of IL-17A in axial spondyloarthritis and psoriatic arthritis: recent advances and controversies. Ann Rheum Dis 2019;78:1167-78.

2 Queiro R, Lorenzo A, Tejón P, et al. Obesity in psoriatic arthritis. Comparative prevalence and associated factors. Medicine 2019;98:e16400.

3 Højgaard P, Glintborg B, Kristensen LE, et al. The influence of obesity on response to tumour necrosis factor- $\alpha$ inhibitors in psoriatic arthritis: results from the DANBIO and ICEBIO registries. Rheumatology 2016;55:2191-9.

4 Notario J, Deza G, Vilarrasa E, et al. Treatment of patients with plaque psoriasis with secukinumab in a real-life setting: a 52-week, multicenter, retrospective study in Spain. J Dermatolog Treat 2019;30:424-9.

5 Taylor W, Gladman D, Helliwell P, et al. Classification criteria for psoriatic arthritis: development of new criteria from a large international study. Arthritis Rheum 2006;54:2665-73.

6 Queiro R, Lorenzo A, Tejón P, et al. Obesity in psoriatic arthritis: comparative prevalence and associated factors. Medicine 2019;98:e16400. 